\title{
Kamil' Basirovich Sabitov (A Tribute in Honor of His Sixtieth Birthday)
}

DOI: $10.1134 /$ S0012266111060012

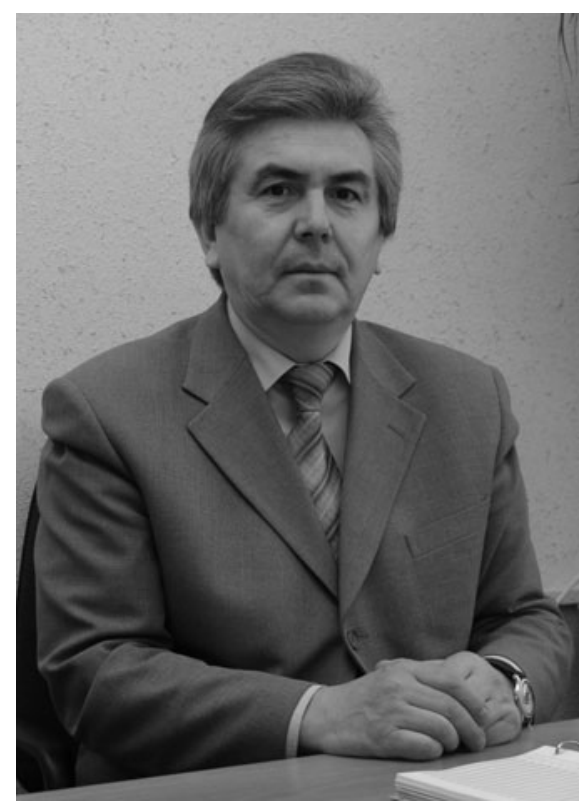

On May 1, 2011, the famous Russian scientist Kamil' Basirovich Sabitov, a distinguished specialist in the field of mathematical physics, partial differential equations, equations of mixed type, and integral and special functions, Doctor of Science (in physics and mathematics), Professor, Corresponding Member of the Bashkir Academy of Sciences, celebrated his sixtieth birthday. The Editorial Board of the journal "Differential Equations" cordially wish him many happy returns of the day, new successes in his many-sided activity, good health, and prosperity. 